\title{
PERFORMANCE AND SELECTIVITY OF CERAMIC MEMBRANES IN THE ULTRAFILTRATION OF MODEL EMULSION IN SALINE
}

\author{
Konrad ĆWIRKO, Agnieszka KALBARCZYK-JEDYNAK \\ Maritime University of Szczecin
}

\begin{abstract}
:
Oily wastewaters from different onshore and offshore installations and from maritime transport pose a serious threat to the environment so they must be treated by multistage separation also including membrane processes. The main advantages of such membranes are high performance and selectivity, high resistance for temperature and pressure, resistance for acids, bases and solvents, long service life and for application - significant reduction of industries and transport environmental impact. This work presents the results of the process of separation of oil from the emulsion with $\mathrm{NaCl}$ addition. Research was performed with a use of laboratory installation with ceramic $300 \mathrm{kDa}$ membrane. The analysis concerned performance and selectivity of a membrane in the function of time and test results have been subsequently compared with the requirements of the IMO.
\end{abstract}

Key words: ceramic membranes, ultrafiltration, selectivity of membranes, oil emulsions, oily wastewaters, saline emulsions, bilge water, ballast water

\section{INTRODUCTION}

Oily wastewaters containing dispersed oils and suspended matter are produced from diverse industrial sources, such as general metal-working, food processing, transportation, and gas and oil production. Waste streams from onshore and offshore oil and gas operations are among the largest sources of oily wastewaters. The oil content of these waste streams comes to $1000 \mathrm{ppm}$, and causes that they must be treated for both the recycling process and the discharge into the environment. Water streams with concentration of more than $10 \mathrm{ppm}$ oil plug valves and equipment and form heat-insulating films increasing energy consumption of the appliances. Also, more and more stringent environmental requirements impose an obligation to reduce mineral and synthetic oil content down to 5 ppm [1, 2, 3, 4].

A very complex composition of oily wastewater causes the removal of oil and other contaminants to a level compatible with the requirements in a single separation process to be insufficient. Treatment technologies employed for such waste streams are the multistage ones. Typically they consist of pre-treatment (gravitational separation and centrifugation), followed by the removal of oil emulsion (chemical destabilization, flotation, coalescing filters and microfiltration followed by ultrafiltration). The final step is the thorough cleaning with the use of separation processes, such as adsorption on activated carbon or nanofiltration and reverse osmosis $[3,11]$.

In the hybrid technologies there were widely applied pressure membrane processes such as MF (microfiltration), UF (ultrafiltration), NF (nanofiltration) and RO (reverse osmosis) that were based primarily on ceramic membranes, characterized by high chemical and thermal resistance $[1,2$, $4,5,8]$. The main advantage of the use of membrane separation techniques is the ability to achieve a treated stream (permeate) meeting current and future environmental requirements and significantly reduced, compared to the waste stream undergoing the treatment concentrated stream (retentate), which must then be utilized at the ship or on land [5].

In the literature, there are many papers on the application of membrane processes and polymeric and inorganic membranes for oily wastewater treatment. Reported research are for mostly focused on treatment of wastewater from the petrochemical and refinery industry as well as of oily streams generated on-board (bilge water and ballast water). Authors of the papers focus primarily on the analysis of the impact of the most important operating parameters (transmembrane pressure, TMP, feed velocity over the surface of the membrane, CFV, oil content in the feed, temperature) on the performance of membrane process and oil removal efficiency $[1,2,4,5,6,7,8,9,10,11]$. Only few papers analyzed the influence of the salt content on membrane process [10].

The paper presents the results of the process of separation of oil from the emulsion obtained as a result of ultrasonication with mineral oil and water containing the addition of $\mathrm{NaCl}$. Research was performed with a use of laboratory installation equipped with commercial 23-channel ceramic membranes possessing the filtration area of $0.35 \mathrm{~m}^{2}$. Tests were carried out employing an ultrafiltration membrane with a cut-off $300 \mathrm{kDa}$ under defined process conditions. During ultrafiltration tests the membrane installation/system was working in a semi-open mode, with contin- 
uous discharge of permeate and retentate being recycled constantly. Test analysis concerned performance and selectivity of a membrane, both depending on time. Performance of the membrane was characterized by the volume flow of permeate, JV $\left[\mathrm{m}^{3} / \mathrm{m}^{2} / \mathrm{s}\right]$ and selectivity by the degree of oil rejection, RO [\%]. At a course of long-term ultrafiltration tests values of JV were measured and oil content was determined in the samples of feed, retentate, and permeate based on turbidity measurements. The test results have been compiled in the form of figures and tables and subsequently compared with the requirements of the IMO.

\section{EXPERIMENTAL}

Test runs were performed in the system as shown in Fig. 1. Experimental set up has been equipped with industrial ceramic tubular membranes with cut-off 300 kDa (Fig. 2).

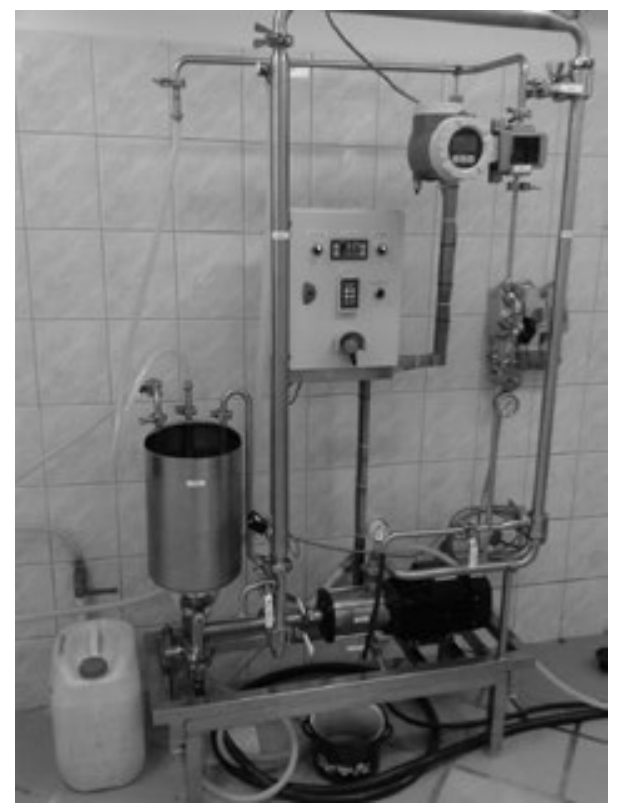

Fig. 1 Membrane installation used in experiments Source: [Konrad Ćwirko].

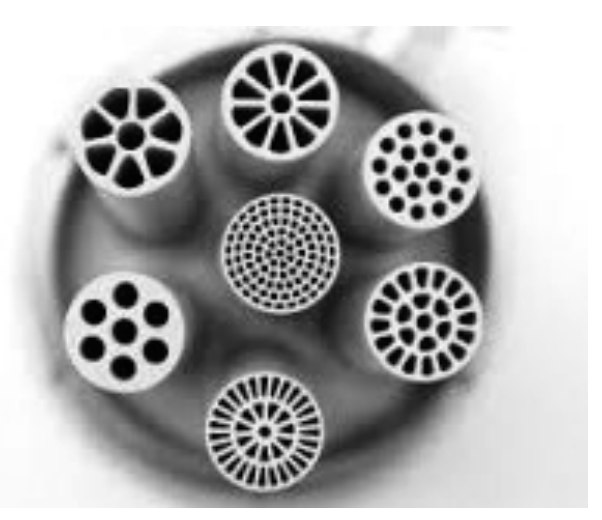

Fig. 2 Ceramic tubular membranes with different number of channels

Source: [info TAMI].

Feed model solutions used in the test runs were of composition water-oil and water-oil-sodium chloride. Model solutions in an amount of $10 \mathrm{dm}^{3}$ (minimum volume recommended by the manufacturer of the system) were prepared as an oil in water emulsions, with and without the addition of $\mathrm{NaCl}$, at a concentration of 1 and $3.5 \%$. An oil-water emulsion was prepared using ultrasonic processor VCX-500
Sonics and the following operating parameters: frequency of $20 \mathrm{kHz}$, the vibration amplitude of peak-to-peak resonator: $124 \mu \mathrm{m}$, resonator diameter $13 \mathrm{~mm}$, temperature $22^{\circ} \mathrm{C}$, scattering time $5 \mathrm{~s}$, oil injection directly into the resonator a distance approx. $5 \mathrm{~mm}$, power density in the injection zone of about $20 \mathrm{~W} / \mathrm{cm}^{2}$. Hydraulic oil HYDROL LHL 46 was used in the process of homogenization, at a concentration of $500 \mathrm{ppm}$ employing also a pipette HTL V3 possessing volume of $1000 \mathrm{ml}$ and interchangeable tips [12]. After completion of the emulsion, it was in each case immediately proceeded to run the ultrafiltration test in order to maintain the structure of prepared solutions. Ultrafiltration tests were under conditions of CFV in the range of 2.75-6.0 m/s, TMP in the range of $0.05-0.2 \mathrm{MPa}$ and constant temperature of $25^{\circ} \mathrm{C}$. The flow rate of the feed $\mathrm{F}$, at a surface of the membrane i.e. CFV was determined from the graph of pressure drop in the membrane module (Figure 3).

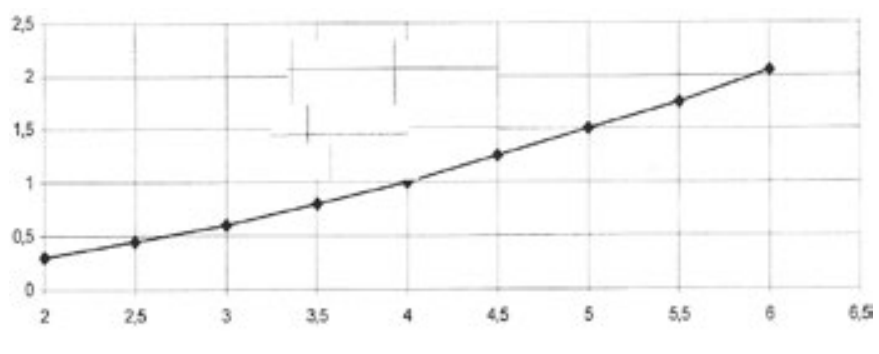

Fig. 3 Pressure drop in a module (bar) vs. feed velocity $(\mathrm{m} / \mathrm{s})$ for 23-channel membrane (manual of the installation, manufacturer's description)

At a course of each ultrafiltration run samples of feed $F$, permeate $P$ and retentate $R$ were collected at specified time intervals. In the samples of $F, P$ and $R$ turbidity was determined to calculate the retention coefficient (Eq. 2). Volume flow of the permeate, $J_{v}$ was calculated from the measurements of the volume of permeate, $V_{p}$ collected during the time (Eq. 1). The duration of each of the ultrafiltration process was determined for 10-15 minutes. After each test, the UF membrane module and the installation were chemically cleaned up following the procedure recommended by the manufacturer, until the membrane reaches that hydraulic permeability of a clean membrane $[13,14]$.

Volume flow of permeate (the membrane performance), JV $\left(\mathrm{m}^{3} / \mathrm{m}^{2} \mathrm{~s}\right)$ was calculated using the equation (1):

$$
J_{V}=V_{P} /(\tau \cdot S)
$$

where:

$\mathrm{V}_{\mathrm{p}}$ - volume of permeate sample, $\mathrm{m}^{3}$,

$\tau$ - time of collection of permeate sample of a volume of $V_{P}$, $\mathrm{S}-$ membrane $(300 \mathrm{kDa})$ filtration surface, $0.35 \mathrm{~m}^{2}$.

The degree of oil rejection (oil retention coefficient), RO that characterizes the selectivity of the membrane was calculated with a use of equation (2):

where:

$$
R_{O}=\left(1-C_{P} / C_{N}\right) \cdot 100 \%
$$

$\mathrm{C}_{\mathrm{P}}$ - turbidity of the permeate, NTU,

$\mathrm{C}_{\mathrm{F}}$ - turbidity of the feed, NTU. 


\section{RESULTS AND DISCUSSION}

The influence of operating parameters on performance, $\mathrm{Jv}$ and selectivity of the ceramic membrane $300 \mathrm{kDa}, \mathrm{RO}$ operated in the semi-open system was analyzed from the point of view of the applicability of the membrane in the main stage of a hybrid treatment process of oily and saline waters, in order to meet the requirements of the protection of the marine environment.

Results obtained in the research of the ultrafiltration process for model oil-water and oil-water-sodium chloride solutions with a use of a $300 \mathrm{kDa}$ ultrafiltration membrane are shown in Table 1 and in Fig. 4-Fig. 6.
In the run ultrafiltration tests of model emulsions, the characteristic for membrane processes decrease of the volumetric flow of permeate with time has been observed. This decrease, caused by a fouling is predominantly dependent on such operating parameters like CFV and TMP (Table 1, Fig. 4). Investigated systems has shown that during 10 min ultrafiltration tests, permeate flow was reduced when compared to initial Jv $(\tau=0)$ by $3 \%$ for an emulsion of 0 and $1 \% \mathrm{NaCl}$, and by $2 \%$ in the case of an emulsion of $3.5 \% \mathrm{NaCl}$.

Table 1

Measurement results of ultrafiltration process of oily and saline model solutions with a use of ceramic membrane with $300 \mathrm{kDa}$ cut-off

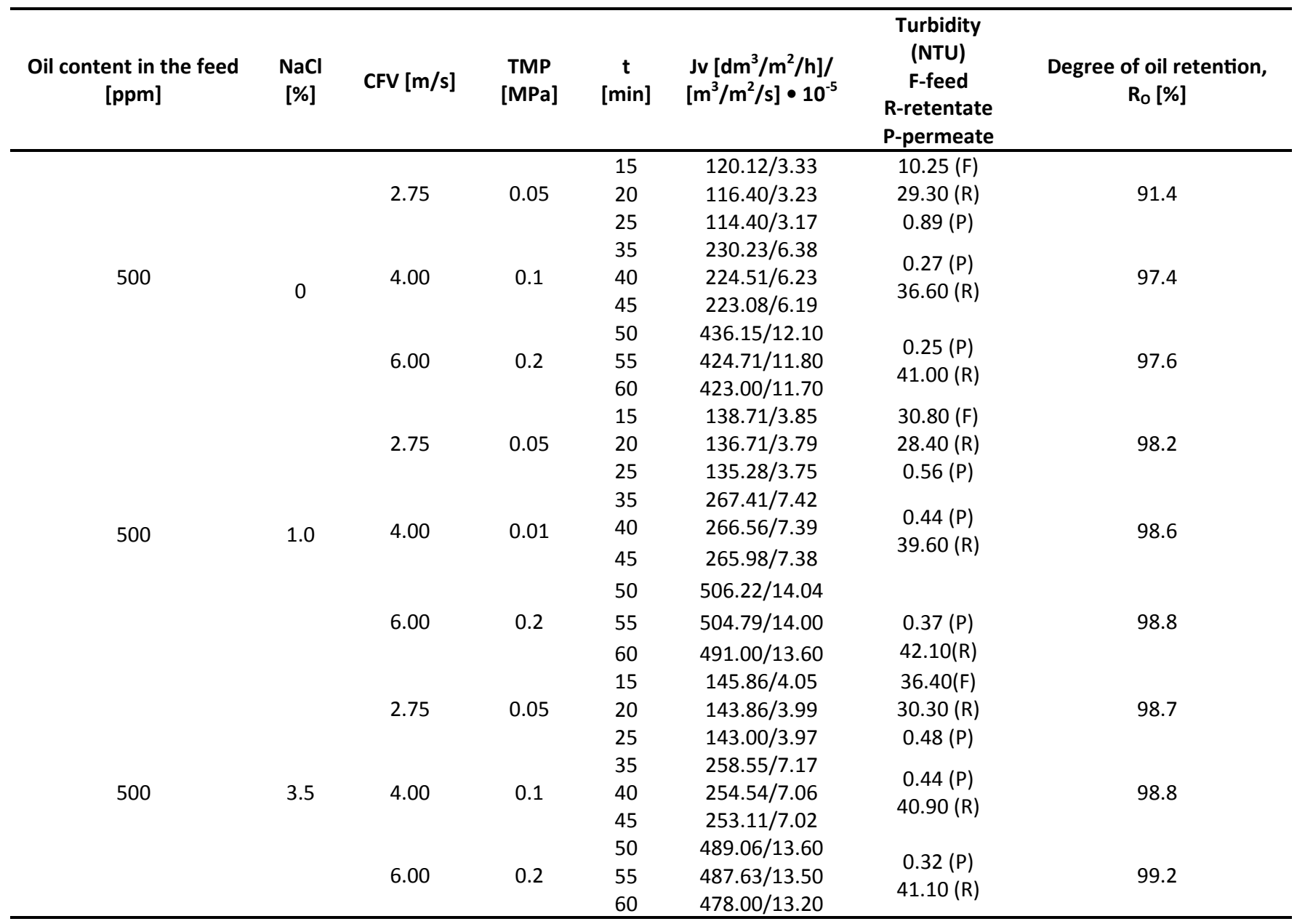

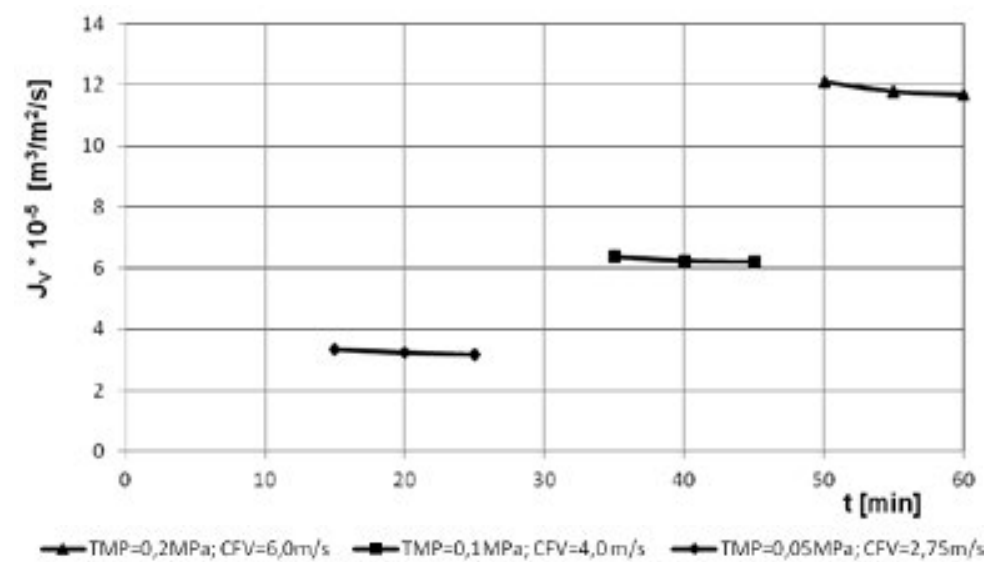




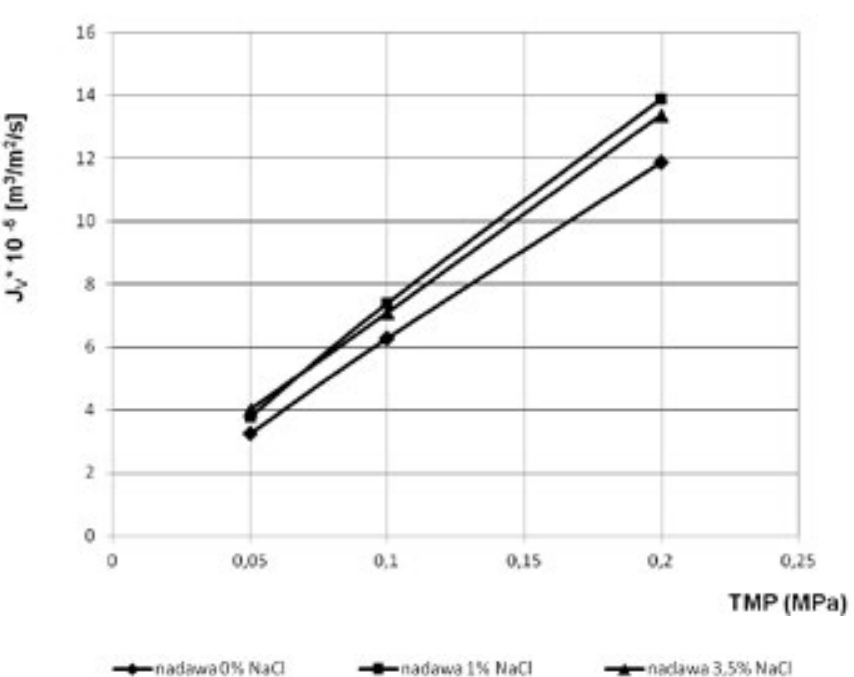

Fig. 5 Impact of TMP on $300 \mathrm{kDa}$ membrane for the system oilwater $(0 \% \mathrm{NaCl})$ and oil-water-sodium chloride (1.0 and $3.5 \%$ $\mathrm{NaCl}$

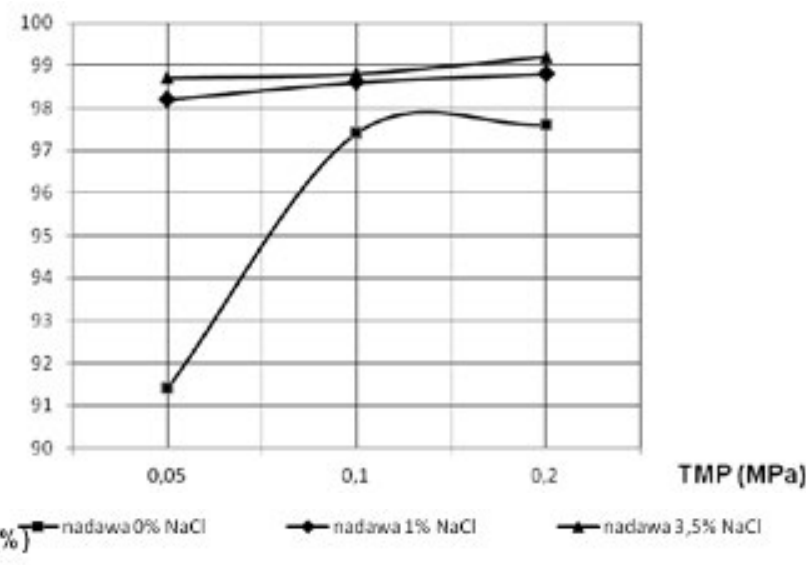

Fig. 6 Impact of TMP on $300 \mathrm{kDa}$ membrane selectivity in the systems of oil-water (0\% $\mathrm{NaCl}$ ) and the oil-water-sodium chloride (1 and $3.5 \% \mathrm{NaCl}$ )

Figure 5 shows the relationship Jv (after 10 min ultrafiltration) vs. TMP and salt concentration in the feed, characterizing the efficiency of the membrane in the water-oil$\mathrm{NaCl}$ system.

As seen from Figure 5 the performance of $300 \mathrm{kDa}$ membrane clearly increases with an increase of TMP and $\mathrm{CFV}$ and is slightly dependent on the concentration of $\mathrm{NaCl}$ in the emulsion undergoing the ultrafiltration. For the systems tested a maximum performance has been reached in a case of a membrane under conditions of turbulent flow, CFV $6 \mathrm{~m} / \mathrm{s}$ at a transmembrane pressure, TMP equal to 0.2 $\mathrm{MPa}$. The volume flow of the permeate, JV amounts under these conditions $11.7 \times 10^{-5}, 13.6 \times 10^{-5}$ and $13.2 \times 10^{-5} \mathrm{~m}^{3} /$ $\mathrm{m}^{2} \mathrm{~s}$, respectively, for the oil-in-water $(0 \% \mathrm{NaCl})$ and oilwater-sodium chloride ( $1 \%$ and $3.5 \% \mathrm{NaCl}$, Table 2 ).

Figure 6 shows the dependence of the level of oil rejection, RO of TMP and CFV as well as of salt content of the emulsion subjected to an ultrafiltration. The dependence characterizes the selectivity of a $300 \mathrm{kDa}$ membrane in water-oil- $\mathrm{NaCl}$ system under the test process conditions.

In the tested systems: $300 \mathrm{kDa}$ membrane-oil-water with 1.0 and $3.5 \%$ sodium chloride, high oil retention coefficients in the range of $98.2-99.2 \%$ were obtained, corresponding to a reduction from the oil content of $500 \mathrm{ppm}$ in the feed to $6-4 \mathrm{ppm}$ in the permeate. For the system: 300 kDa membrane-oil-water, retention of the oil at a level of $97.5 \%$ corresponds to $12.5 \mathrm{ppm}$ of oil in the permeate (Table 2).

Table 2

Results of calculations showing the efficiency and selectivity of $300 \mathrm{kDa}$ membrane in the investigated systems: oil-water and oil-water-sodium chloride; $C_{F}=500 p p m, C F V=6 \mathrm{~m} / \mathrm{s}$, $T M P=0.2 \mathrm{MPa}$

\begin{tabular}{cccc}
\hline $\begin{array}{c}\text { NaCl content } \\
\text { in a feed, [\%] }\end{array}$ & $\mathrm{J}_{\mathrm{V}}\left[\mathrm{dm}^{3} / \mathrm{m}^{2} / \mathrm{h}\right] /\left[\mathrm{m}^{3} / \mathrm{m}^{2} / \mathrm{s}\right]$ & $\mathrm{R}_{\mathrm{O}}[\%]$ & $\mathrm{C}_{\mathrm{P}}[\mathrm{ppm}]$ \\
0 & & & \\
1.0 & $423 / 11.7 \times 10^{-5}$ & 97.6 & 12.5 \\
3.5 & $491 / 13.5 \times 10^{-5}$ & 98.8 & 6.0 \\
\hline
\end{tabular}

As it is apparent from table 2, the salinity of an oil emulsion or efficiency does not decrease neither the performance nor the selectivity of investigated membrane with cut-off $300 \mathrm{kDa}$.

\section{CONCLUSION}

The aim of the work is the research on the removal of oil from saline waters down to the oil contents enabling for the discharge of treated effluent to a clean water environment. The treatment is carried out with the use of ultrafiltration process and ceramic membranes.

Analysis of the literature data and the results of this study indicate the above mentioned may be possible if the suitable membrane system based on selected membranes will be defined and then designed. There will be also essential the optimal process parameters to determine and database characterizing the efficiency and selectivity of such membranes to create.

The performed research shows that the process of ultrafiltration with a use of a ceramic membrane with 300 kDa cut-off enables for the highly removal of oil (97.6$99.2 \%)$ and reduction of an oil content in the treated stream below 15 ppm (12.5-4 ppm). Under turbulent flow conditions, reducing to a minimum fouling in a module (CFV $6 \mathrm{~m} / \mathrm{s}, \mathrm{TMP} 0.2 \mathrm{MPa}), 300 \mathrm{kDa}$ ultrafiltration membrane possesses a high performance in the range of $423-491 \mathrm{dm}^{3}$ / $\mathrm{m}^{2} \mathrm{~h}$ while maintaining a high selectivity. Moreover, salinity of the emulsion in the range investigated up to $3.5 \%$ does not adversely affect membrane separation properties.

Research will continue. In its subsequent stages there is planned to employ membranes with a smaller hydraulic diameter in order to obtain the technological database to design a system in a configuration of membrane cascade enabling both to obtain a treated stream (permeates) that meets the requirements of the protection of the marine environment and to minimize a volume of a concentrated stream (retentates), stored on board during transportation, and then placed into disposal on land.

Research has been financed under the grant of the Ministry of Science and Higher Education no $2 / \mathrm{S} / \mathrm{KFiCh} / 15$

\section{REFERENCES}

[1] S.R.H. Abadi, M.R. Sebzari, M. Hemati, F. Rekabdar and T. Mohammadi. "Ceramic membrane performance in microfiltration of oily wastewater", Desalination, vol. 265, no. 1-3, Jan. 2011, pp. 222-228. 
[2] N.A. Ochoa, M. Masuelli and J. Marchese. "Effect of hydrophilicity on fouling of an emulsified oil wastewater with PVDF/PMMA membranes", J. Membrane Sci., vol. 226, no. 1-2, Dec. 2003, pp. 203-211.

[3] R. Marecik, P. Cyplik and Ł. Chrzanowski. "Oczyszczanie ścieków rafineryjnopetrochemicznych", Ecomanager, vol. 11, 2011, pp. 20 $-21$.

[4] J.M. Benito, M.J. Sanchez, P. Pena and M.A. Rodriguez. "Development of a new high porosity ceramic membrane for the treatment of bilge water", Desalination, vol. 214, no. 1-3, Aug. 2007, pp. 91-101.

[5] R. Ghidossi, D. Veyret, J.L. Scotto, T. Jalabert and P. Moulin. "Ferry oily wastewater treatment", Separation and Purification Technology, vol. 64, no. 3, Jan. 2009, pp. 296-303.

[6] R.S. Faibish and Y. Cohen. "Fouling-resistant ceramicsupported polymer membranes for ultrafiltration of oil-in-water microemulsions", J. Membrane Sci., vol. 185, no. 2, Apr. 2001, pp. 129-143.

[7] B. Lin, C.-Y. Lin, T.-C. Jong. "Investigation of strategies to improve the recycling effectiveness of waste oil from fishing vessels", Marine Policy, vol. 31, no. 4, Jul. 2007, pp. 415-420.

[8] M. Ebrahimi, D. Willershausen, K.S. Ashaghi et al. "Investigations on the use of different ceramic membranes for efficient oil-field produced water treatment", Desalination, vol. 250, no. 3, Jan. 2010, pp. 991 $-996$.
[9] H. Peng and A.Y. Tremblay. "Membrane regeneration and filtration modeling in treating oily wastewaters", J. Membrane Sci., vol. 324, no. 1-2, Oct. 2008, pp. 5966.

[10] M. Hesampour, A. Krzyzaniak and M. Nyström. "The influence of different factors on the stability and ultrafiltration of emulsified oil in water", J. Membrane Sci., vol. 325, no. 1, Nov. 2008, pp. 199-208.

[11] H. Peng and A.Y. Tremblay. "The selective removal of oil from wastewaters while minimizing concentrate production using a membrane cascade", Desalination, vol. 229, no. 1-3, Sep. 2008, pp. 318-330.

[12] J. Chmiel, J. Steller, A. Krella and W. Janicki. "Badania zużycia korozyjno-kawitacyjnego na stanowisku wibracyjnym ze spoczywająca próbką", Problemy eksploatacji, vol. 76, no. 1, 2010, pp. 91-100.

[13] International Convention for the Prevention of Pollution from Ships, 1973, as modified by the Protocol of 1978 relating thereto (MARPOL 73/78) - Annex V, Dz. U. 1987.17.101 2005.07.29 uzup. Dz. U. 2005.202.1679

[14] M. Skrzypek. Instrukcja użytkowania instalacji membranowej, INTERMASZ, 2013. mgr inż. Konrad Ćwirko, dr inż. Agnieszka Kalbarczyk-Jedynak Maritime University of Szczecin, Division of Mechanics Wały Chrobrego 1-2 Str., 70-500 Szczecin, POLAND

e-mail: k.cwirko@am.szczecin.pl a.kalbarczyk@am.szczecin.pl internetowej czasopisma.
The article in Polish language version available on the website of the journal 